\title{
Entrepreneurship
}

Jul a Dez $2019-$ v.3 - n.2

ISSN: 2595-4318

This article is also available online at: www.sustenere.co

\section{Caracterização da gestão de pessoas na administração pública de municípios do sul do estado de Minas Gerais}

O presente trabalho aborda a Gestão de Pessoas na Administração Pública de Municípios da região Sul do Estado de Minas Gerais. Propõe-se a buscar correlações entre a forma de organização e gerenciamento do governo municipal, especificamente no que se refere à administração de seu pessoal, buscando caracterizar a gestão de pessoas na esfera pública municipal na região pesquisada. A pesquisa é de natureza exploratória, com utilização de questionários on-line e físico como instrumentos de coletas de dados, e utilização do software SPSS 21 para realização das análises descritivas e multivariadas dos dados. Utilizou-se de amostragem por conveniência em virtude da pouca adesão dos municípios envolvidos. Os resultados demonstraram que, ainda que exista o setor de RH, as práticas de gestão de pessoas no setor público ainda não atuam de forma estratégica. Municípios de população maior demonstram ter práticas mais estruturadas, envolvendo principalmente os processos de treinamento e remuneração dos trabalhadores.

Palavras-chave: Gestão de pessoas; Setor Público; Administração de pessoal.

\section{Characterization of the management of people in the public administration of municipalities of the south of the state of Minas \\ Gerais}

This paper deals with the People Management in the Public Administration of Municipalities in the southern region of the State of Minas Gerais. It proposes to seek correlations between the form of organization and management of the municipal government, specifically with regard to the administration of its personnel, seeking to characterize the management of people in the municipal public sphere in the region surveyed. The research is exploratory, using online and physical questionnaires as instruments of data collection, and SPSS 21 software to perform the descriptive and multivariate analyzes of the data. Convenience sampling was used because of the poor adherence of the municipalities involved. The results showed that, although the Human Resources sector exists, the practices of people management in the public sector still do not act strategically. Municipalities with a larger population show more structured practices, mainly involving the training and compensation of workers.

Keywords: People Management; Public Sector; Administration of Personnel.

Topic: Gestão Pública

Reviewed anonymously in the process of blind peer
Received: 14/07/2019

Approved: 27/11/2019
Ernani de Souza Guimarães Júnior

Centro Universitário do Sul de Minas, Brasil

http://lattes.cnpq.br/6063005535270998

ernani.junior@unis.edu.br

Pedro dos Santos Portugal Júnior (id

Centro Universitário do Sul de Minas, Brasil

http://lattes.cnpq.br/3402598684545658

http://orcid.org/0000-0003-2590-1959

pedro.junior@unis.edu.br

Sheldon William Silva (i)

Instituto Federal do Norte de Minas Gerais, Brasil

http://lattes.cnpq.br/5691436224279198

http://orcid.org/0000-0002-2473-5728

sheldonwilliamsilva@gmail.com

\author{
Alessandro Messias Moreira (id \\ Centro Universitário do Sul de Minas, Brasil \\ http://lattes.cnpq.br/5303526458310366 \\ http://orcid.org/0000-0001-8120-6219 \\ alessandro.moreira@unis.edu.br \\ Fabrício Pelloso Piurcosky (ic \\ Universidade Federal de Lavras, Brasil \\ http://lattes.cnpq.br/9736654155430529 \\ http://orcid.org/0000-0001-5458-5129 \\ fabricio@unis.edu.br
}

Referencing this:

GUIMARÃES JÚNIOR, E. S.; PORTUGAL JÚNIOR, P. S.; SILVA, S. W.; MOREIRA, A. M.; PIURCOSKY, F. P.. Caracterização da gestão de pessoas na administração pública de municípios do sul do estado de Minas Gerais. Entrepreneurship, v.3, n.2, p.19-33, 2019. DOI: http://doi.org/10.6008/CBPC2595-4318.2019.002.0003 


\section{INTRODUÇÃO}

Este trabalho busca caracterizar a Gestão de Pessoas na Administração Pública de Municípios da região Sul do Estado de Minas Gerais, tomando como referência as regiões de planejamento do Governo do Estado. A pesquisa buscou identificar como é feita a gestão de pessoas e quais as práticas mais comuns em três diferentes processos: treinamento, avaliação de desempenho e remuneração. A abordagem da questão se justifica ao tentar responder à pergunta: como é feita a gestão de pessoas no setor público de pequenos e médios municípios do Estado de Minas Gerais?.

Considerando todo o processo evolutivo do Estado brasileiro, é notável que o país tenha passado por grandes mudanças a partir dos anos 1980 e 1990. O Estado brasileiro, mesmo em processo contínuo de reforma, ainda mantém algumas características históricas arraigadas em muitas práticas ao longo dos séculos. Ponderando que a mudança da estruturação do Estado é uma tendência mundial e que não se operacionalizou de forma ampla no Brasil, maior dificuldade é encontrada na esfera municipal, onde as práticas históricas de deturpação do poder público (patrimonialismo, nepotismo, clientelismo, entre outras) são ainda mais fortes.

O propósito deste estudo mostra-se alinhado ao desejo de identificar a existência de traços da administração pública gerencial associados à gestão de pessoas em municípios da região do Sul de Minas Gerais, manifestado por meio da organização e características do serviço. Busca também caracterizar quais práticas e instrumentos são mais utilizados para administração de pessoal nas prefeituras.

Como primícias o estudo apresenta três hipóteses: 1) As práticas de gestão de pessoas na administração pública municipal estão voltadas para o controle de pessoal (Departamento de Pessoal); 2) As prefeituras com mais de 100 mil habitantes, possuem práticas de gestão de pessoas mais bem elaboradas; 3) As prefeituras não possuem setor específico de Recursos Humanos / Gestão de Pessoas.

Há que se considerar também que o gasto público municipal com pessoas envolve grande percentual de todo o recurso público aplicado. Segundo a Lei Complementar 101 (BRASIL, 2000), o limite permitido de gasto com pessoal para os municípios é de até $60 \%$ da arrecadação, contabilizando o legislativo e o executivo. Para o poder executivo o limite é de $54 \%$ da receita corrente líquida. Para acompanhamento e controle do gasto com pessoal, foram definidas cinco categorias, apresentadas na Tabela 1.

Tabela 1: Limites de Gastos com Pessoal no setor público municipal (executivo).

\begin{tabular}{|l|l|}
\hline \% do Gasto com pessoal & Situação \\
\hline Menor que $41 \%$ & Boa \\
\hline De $41 \%$ a $45,9 \%$ & Ajustada \\
\hline De $46 \%$ a $51 \%$ & Limítrofe \\
\hline De $51 \%$ a $54 \%$ & Emergencial \\
\hline Acima de $54 \%$ & Limite estourado \\
\hline
\end{tabular}

Fonte: Reproduzido de CNM (2017).

O poder público municipal é acionado toda vez que o limite prudencial atinge $95 \%$ do gasto possível com o poder executivo, a saber, 51,3\%. Essa é considerada a situação limítrofe. Segundo dados da Confederação Nacional dos Municípios (CNM, 2017), em 2017, 28,5\% dos municípios estavam na situação limítrofe enquanto que $26,1 \%$ deles já estão com o limite estourado. 
O que se quer evidenciar com esses dados é a importância do gasto com pessoal no orçamento municipal, motivo pelo qual dever-se-ia ter uma gestão melhor da eficiência da aplicação do recurso, o que necessariamente se direciona a fazer uma gestão de pessoas efetiva e estratégica. $O$ estudo encontra-se organizado em cinco partes, sendo essa introdução a primeira. A segunda busca contextualizar teoricamente o Estado e a administração pública, bem como a gestão de pessoas. A terceira parte apresenta os processos metodológicos empregados na pesquisa. A quarta parte apresenta e discute os resultados da pesquisa e na quinta e última apresentam-se as considerações finais do estudo.

\section{REVISÃO TEÓRICA}

\section{Estado e Administração Pública}

Desde o Varguismo, passando pelo período da ditadura até chegar à redemocratização observam-se mudanças significativas na forma de atuação do Estado brasileiro dentro de seu processo de consolidação e desenvolvimento. Arraigado em sua tradição patrimonialista, cujas raízes podem ser atribuídas ao próprio modelo de colonização utilizado por Portugal, buscou-se na construção weberiana de estado burocrático formas de se atingir a racionalidade e impessoalidade do Estado, com foco em uma maior eficiência (ARAGÃO, 1997).

Ocorre que na busca de controlar o patrimonialismo cai-se em uma burocracia exagerada que impede o dinamismo do Estado no Brasil. Alternativas são apresentadas para tentar superar esse impasse, como a criação do Departamento Administrativo do Serviço Público (DASP) em 1938, a Comissão de Simplificação Burocrática (CoSB), vinculada ao DASP, em 1956, a Comissão de Estudos de Reforma Administrativa (Comestra) em 1964 e o próprio Ministério da Desburocratização criado em 1979 e vigorando até 1986 (ANDRADE, 2017).

Nos anos 1980, a crise do Estado Brasileiro começa a se expor de maneira mais reveladora. O modelo de desenvolvimento estabelecido na industrialização substitutiva de importações dos anos 1930 começa a se esgotar. Nesse cenário de profundas mudanças, não tardou para que se voltasse o debate e as manifestações populares a favor da redemocratização do Estado e de seu aparelho burocrático, o que, de maneira inevitável, levou ao término do regime militar. A partir de então o Estado precisou se reinventar.

Toda essa discussão chegou à Constituição de 1988, sem que houvesse uma solução aos velhos problemas. Continuaram-se as tentativas, como a própria criação do Ministério de Administração Federal e Reforma do Estado (MARE) na década de 1990, capitaneado por Luiz Carlos Bresser-Pereira, que dentre outras finalidades, trazia o desejo de construção de um novo modelo de administração pública para o país (ANDRADE, 2017).

O modelo proposto para o Brasil se sustenta na concepção de que em sociedades modernas, o Estado se coloca como instituição central, sendo responsável pela organização, pela promoção do desenvolvimento econômico e pela oferta de serviços essenciais à população. Reforça a ideia, o fato de que desde a II Grande Guerra, a flexibilidade passou a ser condição na busca de desenvolvimento econômico dos Estados. Assim, 
nos anos 80 surgiu a necessidade que isso fosse acompanhado de uma nova forma de administrar, nascendo a Nova Gestão Pública (BRESSER-PEREIRA, 1997).

Bresser-Pereira (1998) propôs um padrão estrutural de gerência pública, procedente das práticas desenvolvidas pelas organizações particulares durante o século XX. O feitio reformador gerencial busca tornar a administração mais flexível e os administrados e administradores mais motivados. Para que isso ocorra é necessária uma reforma estrutural do Estado. Ainda segundo o autor, o perfil dos novos funcionários públicos está limitado às pessoas já graduadas, treinadas e bem pagas, e, por consequência, Ihe serão exigidos elevados padrões de competência. Estes devem possuir autonomia e serem responsabilizados respectivamente por isso, além de lidar com ideias e decisões ao invés de produtos e serviços. Sendo assim, observa-se a intenção da reforma gerencial em tornar os funcionários públicos mais autônomos e responsáveis. Para o autor, "uma estratégia essencial ao se reformar o aparelho do Estado é reforçar o núcleo estratégico e o fazer ocupar por servidores públicos altamente competentes, bem treinados e bem pagos" (BRESSER-PEREIRA, 1998).

Foi então em meados de 1995 que o Brasil chegou à primeira grande reforma administrativa de seu recente período democrático. A reforma do Estado pregava uma Reforma da Administração Pública por meio da criação de um modelo pós-burocrático que, a partir dos alicerces da matriz de profissionalização weberiana, procurou transformar os procedimentos da gerência pública em setores como educação, saúde, saneamento, habitação para a administração local ou governos estaduais.

Bresser-Pereira (1997) apresenta uma proposta específica de reforma do Estado: o Modelo Estrutural de Gerência Pública. Esse modelo busca mudanças na estrutura organizacional e na forma de gerenciamento do Estado. Defende a gestão pública como instrumento ideologicamente neutro, podendo servir tanto a interesses conservadores como progressistas.

O Modelo Estrutural de Gerência Pública de Bresser-Pereira (1997) comporta dois aspectos: o Gerencial ou de Responsabilização (como administrar todo o sistema) e o Organizacional ou Estrutural (como estruturar os serviços do Estado, ou seja, o que Ihe pertence e o que deve ser terceirizado)

Essa proposta, que se caracteriza por traços de um modelo gerencial privado, manifestava a clara necessidade, cada vez mais imperiosa de responder aos problemas nacionais, respaldado por princípios como “eficiência, eficácia, efetividade, legitimidade democrática, impacto das tecnologias da informação na administração, entre outros" (MATIAS-PEREIRA, 2008).

A aproximação da gestão pública com o modelo desenvolvido pela iniciativa privada torna-se evidente. Bergue (2010) considera que essa aproximação traz uma nova realidade e delineamentos à gestão pública, como uma estrutura mais enxuta, administração descentralizada, flexibilidade organizacional e maior controle de todos os processos. Ainda reforça que novas tecnologias gerenciais são apresentadas à gestão pública, como a possibilidade de terceirização de serviços, o empoderamento, a gestão por processos e por competências, a governança entre outros. 
Transposição de práticas de gestão da inciativa privada para o setor público.

A discussão entre público e privado no Brasil é amplamente analisada, inclusive sob outras óticas, já que o conflito entre essas dimensões caracteriza a história da administração pública do país. Porém, a discussão que interessa nesse estudo aborda a compreensão das práticas de gestão utilizadas nas duas esferas, ou seja, a adoção de práticas de gestão do setor privado no setor público.

Ao se pensar em uma Administração Pública Gerencial o argumento da eficiência é um dos pilares. Eficiência no gasto e no serviço. A ideia de eficiência é própria da iniciativa privada, assim, a adoção de práticas gerenciais da iniciativa privada na gestão pública tem sido apresentada como uma tendência mundial. A busca por maior eficiência e otimização dos recursos e qualidade dos serviços requer ações planejadas e que direcionem o posicionamento da administração pública em curto, médio e longo prazo (MOTTA, 2004). Quanto à eficiência e sua importância dentro do setor público, vale destacar a percepção de Moreira Neto (2008) ao afirmar que

Essa eficiência, exigida das organizações dotadas de poder - políticas, econômicas ou sociais - passou a ser vital no processo de globalização, alçada a imperativo não só de desenvolvimento como da própria sobrevivência desses entes, inclusive dos próprios Estados, em um mundo em que as demandas não podem deixar de ser atendidas a

contento: sejam pelas instituições públicas, sejam pelas instituições privadas.

Há, no entanto, que se fazer uma reflexão sobre a transposição de técnicas da iniciativa privada para o setor público. Para isso, essencial é saber o que caracteriza o público e o privado em termos de administração. Nessa direção, pode-se utilizar alguns distintivos entre os dois modelos apresentados por Linn Junior (2010), entre eles o argumento de que o interesse do público se difere do interesse privado, já que o estado deve se pautar pelo interesse democrático, com tratamento igualitário a quem demandar seus serviços. Isso não se aplica à iniciativa privada, que pode se pautar pela seleção das melhores propostas e condições de prestação serviço, dando-se o direito de restringir e direcionar a ação. Ainda que os objetivos se diferenciem entre as organizações públicas e privadas, existe algo que Ihes aproximam. Como apresentado por Bergue (2014), as

organizações públicas diferem em aspectos de finalidade e assemelham-se em termos de fundamentos de seus sistemas de gestão. Há interdependência (mutua influência) entre os contornos do sistema de gestão e a natureza da organização, certamente, mas os fundamentos conceituais e pressupostos da organização são intercambiáveis. [...] Organizações públicas e privadas diferem essencialmente em objetivos e se aproximam em meios (sistemas de gestão).

A partir de tais constatações, a adoção de práticas de gestão provenientes da administração privada não fere os princípios da administração pública, pois não estão associadas aos seus objetivos, mas aos meios que o Estado utilizará para atingi-los. Isso se aplica em todos os processos de gestão, inclusive no que tange à gestão de seu capital humano.

\section{Gestão de Pessoas}

A compreensão do que seja a gestão de pessoas sintetiza o que possa caracterizar a organização. Como aponto Bergue (2014), "a organização é uma teia de relações que se estabelecem por meio das 
pessoas. A gestão das organizações se processa, portanto, a partir das pessoas". Quando se fala sobre o tema 'gestão de pessoas' é preciso ter consciência de que não é uma realidade que sempre existiu, pois, os funcionários nem sempre foram o principal ativo de uma organização e para muitas delas esse discurso ainda não se incorpora em suas práticas.

Desde o início da administração científica, Taylor defendia a ideia de planejar melhor e aplicar métodos durante o trabalho e, por consequência, tornar os operários cada vez mais experientes e ágeis em suas atividades. Com isso observa-se que os trabalhadores eram tratados como máquinas e suas motivações não eram relevantes para os gestores, apenas seus resultados. Desde os estudos humanistas iniciados por Elton Mayo encontram-se posições contraditórias. A fim de obter melhores resultados, deu-se início à valorização das relações humanas, uma vez que "as Relações Humanas constituem um processo de integração de indivíduos numa situação de trabalho, de modo a fazer com que os trabalhadores colaborem com a empresa e encontrem satisfação de suas necessidades sociais e psicológicas" (GIL, 2007).

Também corrobora com esse posicionamento a visão de Bergue (2014), uma vez que "a compreensão da gestão não pode ser reduzida ao modelo mecanicista, de inspiração taylorista, baseado na divisão do trabalho e na especialização de conhecimento e tarefas, no exercício da autoridade assentada na hierarquia". A gestão de pessoas eficiente é capaz de influenciar todo o clima organizacional e é notável que as organizações que possuem um bom clima organizacional são merecedoras do reconhecimento de seus colaboradores e com isso obtém um retorno maior, pois são consequências do comprometimento do funcionário para com ela.

Uma gestão de pessoas eficiente tem se associado de forma cada vez mais contundente com a consecução dos objetivos organizacionais. Nessa direção, Ulrich (1998) apresenta a necessidade de que os processos de gestão de pessoas estejam alinhados às mudanças do mercado e inovações, de forma cada vez mais estratégica. Corrobora com essa percepção os escritos de Lacombe (2006), que reconhece que as pessoas não precisam ser mais administradas, mas ao contrário, precisam participar do negócio, tal como seus verdadeiros parceiros.

Ulrich et al. (2011) apontam que as atividades de gestão de pessoas assumem uma posição cada vez mais estratégica, ainda que pautada em alguns processos. Ganha força nesse modelo de gestão a medição da contribuição apresentada pelas pessoas aos resultados do negócio. Isso envolve buscar as melhores pessoas para as atividades, o desenvolvimento de habilidades ou competências necessárias para os bons resultados, administração de prioridades e cargas de trabalho, entre outros. Para Bergue (2014) "a área de gestão de pessoas - em especial no conjunto de competências técnicas e gerenciais de seus profissionais constitui outro importante vetor de fomento ao desenvolvimento de um pensamento estratégico em gestão de pessoas".

A nova concepção de gestão de pessoas reconhece os líderes como verdadeiros gestores do capital humano, e não mais um setor isolado, como era o RH. Para auxiliar as lideranças nessas atividades de gestão de pessoas dentro das organizações surge o papel do profissional de $\mathrm{RH}$ como consultor interno, chamado por Ulrich et al. (2011) de business partner. Ainda segundo esses autores, a gestão de pessoas pode passar a 
ser chamada gestão de talentos, onde talento se traduz na somatória de competência, comprometimento e contribuição.

\section{Gestão de pessoas no setor público}

Para Carmo et al. (2014), as transformações globais que influenciam a administração pública fazem com que a gestão de pessoas apareça como área essencial para um melhor desempenho estatal, principalmente porque o setor público é intenso em mão de obra. A considerar os altos investimentos de recursos financeiros com pessoal dentro do serviço público, em especial no serviço público municipal que é objeto desse estudo, a preocupação em gerenciar esse ativo torna-se cada vez mais importante. Para Bergue (2014) gestão de pessoas no setor público

é a articulação de esforços de gestão orientados para o suprimento, a manutenção e o desenvolvimento de pessoas observados os valores culturais - de natureza social, política, jurídica e econômica - que moldam as condições do contexto em que se inserem as organizações públicas.

Todo o gerenciamento feito em torno do pessoal que compõem as organizações públicas deve estar alinhado ao conceito trabalhado por Dutra (2009), onde "gestão de pessoas consiste na capacidade de mobilizar os colaboradores para o alcance dos objetivos organizacionais". Isso é possível quando os gestores possuem conhecimento da função que exercem, em aspectos como avaliação, progressão, capacitação e também na política de remuneração, pois isso tudo propicia uma parceria entre a organização e os funcionários.

Observa-se que o papel da liderança é fundamental quando envolve gestão de pessoal. Bergue (2014) considera que uma gestão estratégica de pessoas, depende em menor grau de estrutura da organização, e mais da forma e intensidade com que os gestores conseguem transferir isso para o dia a dia de suas ações. Nessa direção tornam-se evidentes as recomendações feitas por esse mesmo autor a respeito da gestão de pessoas no setor público: O gerenciamento de pessoas deve se tornar compromisso de todos os gestores da administração; A organização deve ser reconhecida como um sistema social em permanente interação com seu contexto (tempo e espaço).

Há que se destacar, no entanto, a complexidade que envolve todo o fenômeno da gestão de pessoas, de forma especial dentro do setor público. Ainda que utilize da fundamentação cartesiana para compreender tal fenômeno, ela será ainda insuficiente. A análise mecanicista, muito utilizada pela administração, consegue apresentar sua contribuição para o estudo e análise das organizações em toda a sua diversidade, porém há uma dimensão humana que sempre deve ser considerada (BERGUE, 2014). Bergue (2014) acrescenta, ainda, considerando o paradigma mecanicista utilizado para compreensão das organizações, que

é preciso reconhecer seus limites, que se acentuam quando se estende o olhar para a dimensão humana das organizações públicas. As pessoas e suas relações sociais são sempre fenômenos que só podem ser compreendidos em seu contexto, motivo pelo qual as noções de complexidade e caos têm se revelado marcos conceituais potentes para o diagnóstico e a ação em matéria de gestão de pessoas.

Muitos desafios ainda existem à gestão de pessoas no setor público, sendo que merece destaque a concepção de carreiras alternativas ao modelo hoje utilizado e "admitir que além de possível, pode mesmo 
ser desejável que servidores atuem em organismos outros da administração pública que não aquele para o qual prestaram concurso originalmente" (BERGUE, 2014). O século XXI apresenta um novo cenário para os mercados e a administração, tanto no setor público, quanto no privado. Assim, os desafios da gestão de pessoas se aplicam à sua operacionalização de modo amplo, onde quer se seja utilizado.

\section{MATERIAIS E MÉTODOS}

A presente pesquisa apresenta caráter descritivo e natureza exploratória, uma vez que possui como objetivo informar sobre situações, fatos, opiniões ou comportamentos dos municípios do Sul de Minas Gerais, buscando caracterizar a forma como é realizada a gestão de pessoas (e seus processos) em seus territórios. A pesquisa descritiva, segundo Rudio (1992) "está interessada em descobrir e observar fenômenos, procurando descrevê-los, classificá-los e interpretá-los."

Foram utilizados dados primários advindos de questionário eletrônico e físico contendo questões padronizadas feitas igualmente aos participantes. O instrumento de coleta foi disponibilizado aos responsáveis pelas secretarias de administração ou departamentos de pessoal das prefeituras participantes, utilizando endereços de e-mails oficiais ou sendo entregues em mãos nos respectivos departamentos. Foi direcionado a todos os municípios que compõem a região Sul do Estado de Minas Gerais, conforme regiões de planejamento do Estado de Minas Gerais, somando um total de 155.

Obteve-se retorno de 29 municípios, uma taxa de 18,7\%. Essa taxa de retorno está abaixo da média de retorno para esse tipo de busca de dados, conforme apresentado por Marconi et al. (2005), que preveem uma média de retorno de $25 \%$. Dessa forma convencionou-se a presente pesquisa como baseada em amostra aleatória por conveniência o que não permite a generalização dos resultados. A análise dos dados quantitativos foi feita por meio de estatística descritiva e multivariada, com o auxílio do software SPSS 21.

\section{RESULTADO E DISCUSSÃO}

A partir do retorno de 29 municípios foi possível chegar aos resultados apresentados a seguir. Iniciase a análise pela verificação da existência de setor específico de RH nos municípios, bem como a sua composição e utilização de indicadores de gestão de pessoas. A partir das informações coletadas, observase que $34,5 \%$ dos respondentes afirmaram que a prefeitura possui um setor específico de $\mathrm{RH}$. 37,9\% o setor funciona conjuntamente como de Departamento Pessoal (DP) e para $24,1 \%$ existe apenas esse último setor (DP).

Uma vez identificada a existência de departamentos específicos nos municípios, parte-se para a caracterização dos profissionais que coordenam os setores de RH e/ou DP nas prefeituras. Em relação à formação acadêmica dos responsáveis por esses setores nas prefeituras, observa-se que $79,2 \%$ afirmam possuir curso superior, enquanto que 20,8\% dizem ter formação de nível técnico e 12,5\% de nível médio. Quanto à área de formação por curso, o que se observa é a predominância da formação superior em administração (33,3\%), seguida por contabilidade, Gestão de RH e Gestão Pública (8,3\%). A Tabela 2, especifica a formação dos responsáveis pelos setores, segundo apontamentos dos respondentes. 
Tabela 2: Formação dos responsáveis pelo setor de Recursos Humanos nos municípios estudados.

\begin{tabular}{|l|l|l|l|}
\hline Nível & Curso & Quantidade & Percentual \\
\hline \multirow{5}{*}{ Superior } & Administração (superior) & 8 & $33,3 \%$ \\
\cline { 2 - 4 } & Contabilidade (Superior) & 2 & $8,3 \%$ \\
\cline { 2 - 4 } & Gestão de RH & 2 & $8,3 \%$ \\
\cline { 2 - 4 } & Gestão Pública & 2 & $8,3 \%$ \\
\cline { 2 - 4 } & Enfermagem & 1 & $4,2 \%$ \\
\cline { 2 - 4 } & Ciência da Computação & 1 & $4,2 \%$ \\
\cline { 2 - 4 } & Letras & 1 & $4,2 \%$ \\
\cline { 2 - 4 } & Matemática & 1 & $4,2 \%$ \\
\cline { 2 - 4 } & Pedagogia & 1 & $4,2 \%$ \\
\hline \multirow{5}{*}{ Técnico } & Administração (Técnico) & 2 & $8,3 \%$ \\
\cline { 2 - 4 } & Contabilidade (Técnico) & 2 & $8,3 \%$ \\
\hline Médio & Ensino Médio & 3 & $12,5 \%$ \\
\hline
\end{tabular}

* Três municípios não especificaram a formação do responsável pelo setor de RH e/ou DP.

Em relação aos profissionais que trabalham na área de $\mathrm{RH}$ das prefeituras, 87,3\% deles são efetivos no município. Normalmente os profissionais que não possuem vínculo efetivo são os coordenadores de setor, que são cargos de confiança do gestor municipal. Ainda assim, em mais de $70 \%$ dos municípios, todos os trabalhadores são efetivos (Tabela 3).

Tabela 3: Percentual de trabalhadores efetivos no setor de RH e/ou DP.

\begin{tabular}{|l|l|l|}
\hline \% de profissionais efetivos & Número de Prefeituras & $\%$ \\
\hline $\mathbf{1 0 0} \%$ & 19 & $70,37 \%$ \\
\hline $\mathbf{5 0}-\mathbf{1 0 0 \%}$ & $\mathbf{5}$ & $18,52 \%$ \\
\hline Menos de $\mathbf{5 0} \%$ & $\mathbf{3}$ & $11,11 \%$ \\
\hline
\end{tabular}

Quanto à utilização de indicadores de RH pelas prefeituras, o mais utilizado é o percentual de despesas com pessoal, utilizado por $75,9 \%$ das participantes. Isso se justifica pela necessidade de controle de gasto com pessoal exigido pela Lei Complementar 101 de 2000 que dispõe sobre a responsabilidade na gestão fiscal (BRASIL, 2000). Além desse indicador, são utilizados ainda indicadores de absenteísmo (34,5\% dos municípios), turnover ou rotatividade de pessoal (27,6\% dos municípios). Dois municípios (6,9\%) afirmaram ter indicadores de satisfação dos funcionários e três (10,3\%) afirmaram não utilizar nenhum indicador. De maneira geral, pode-se considerar que os indicadores não são utilizados de forma estratégica, estando restritos, na maioria dos casos, a uma necessidade legal de acompanhamento. Muitos outros indicadores de RH poderiam ser utilizados para uma gestão mais eficiente.

Um segundo bloco de análise busca caracterizar quais práticas e instrumentos são mais utilizados para administração de pessoal nas prefeituras participantes. Volta-se nesse momento para os processos de RH utilizados na administração pública municipal. A se considerar que os processos são amplos, fez-se o recorte em alguns dos mais importantes dentro de uma administração pautada no referencial da administração gerencial, que são: gestão de desempenho, treinamento e desenvolvimento de funcionários, além das práticas de remuneração. Esses processos refletem os objetivos de monitorar, desenvolver e recompensar as pessoas. Destaca-se que o processo de recrutamento e seleção não foi abordado pelas características próprias de admissão no serviço público, que necessariamente se utiliza de concursos. 


\section{Gestão de desempenho}

Em relação à gestão de desempenho, o que se observou é uma priorização nas poucas ações apresentadas voltadas para avaliação de desempenho, mas sem uma efetiva utilização dos resultados obtidos. Há que se destacar que o processo de gestão do desempenho é mais abrangente que a avaliação do desempenho, sendo essa uma parte do processo de gestão. Ainda assim, mais da metade dos municípios respondentes $(53,6 \%)$ afirmaram não realizar qualquer tipo de avaliação relacionada ao desempenho dos funcionários. Constata-se também que $14,3 \%$ dos participantes realizam tal avaliação para alguns cargos e $32,1 \%$ realizam para todos os cargos. O que se observa é que é uma prática ainda pouco utilizada dentro do setor público.

Quando se analisa o motivo ou objetivo alegado para realização da avaliação do desempenho, das treze prefeituras que disseram de alguma forma avaliar o desempenho de seus funcionários, seis delas $(46,2 \%)$ apresentaram como razão o desejo de verificar o desempenho, eficiência e os problemas dos funcionários; cinco respondentes (38,5\%) alegaram a necessidade de avaliação para promoção no plano de cargos e salários e duas prefeituras $(15,4 \%)$ alegaram a necessidade de efetivação do funcionário, subentendendo-se que se trata de avaliação aplicada no período probatório.

Há que se reconhecer a importância do monitoramento para qualquer processo de gestão. Quando se pensa em acompanhar os funcionários públicos no desenvolvimento de suas atividades tendo vista os objetivos de atender às necessidades da população local, é vital ter instrumentos sistematizados para tal finalidade. Isso se dá pela avaliação de desempenho, que permite reconhecer quanto cada pessoa está contribuindo para os resultados organizacionais.

\section{Treinamento}

Avalia-se agora a questão da preparação dos funcionários para o trabalho, por meio das práticas de treinamento e desenvolvimento. Quando perguntadas sobre a oferta de treinamento aos trabalhadores, $44,8 \%$ dos respondentes afirmaram não existir prática regular de treinamento na prefeitura, sendo oferecidos apenas quando surgem oportunidades, ou seja, sem nenhum planejamento. Outras três prefeituras $(10,3 \%)$ disseram que dificilmente os funcionários realizam treinamento. Assim, $55,1 \%$ dos municípios avaliados afirmaram não ter a prática de treinamentos regulares. No entanto, $34,5 \%$ dos participantes disseram que alguns funcionários recebem treinamento regularmente, sem explicitar quais seriam esses trabalhadores ou os cargos ocupados, enquanto que $10,3 \%$ delas disseram que todos os trabalhadores recebem treinamentos. Quando se trata de treinamento de integração de novos trabalhadores, $27,6 \%$ dos municípios alegram não realizar qualquer iniciativa direcionada a esse fim, enquanto que $48,3 \%$ o realiza para alguns cargos e $24,1 \%$ realiza para todos os cargos.

Há que destacar também que os treinamentos oferecidos, na sua grande maioria, não é parte de um processo planejado de desenvolvimento do trabalhador público. Isso se justifica pela declaração de quase 93\% dos respondentes de que não há um plano de treinamento. Ao serem indagados sobre o incentivo à 
qualificação de seus trabalhadores, 58,6\% dos respondentes pelos municípios afirmaram que não há qualquer auxílio ou benefício associado à capacitação do pessoal. Os outros municípios $(41,4 \%)$ oferecem algum tipo de auxílio, sendo que em 10,3\% há a oferta de bolsa de estudos, em $24,1 \%$ ajuda com transporte, $3,5 \%$ oferece apoio por meio da redução da jornada de trabalho, mesmo percentual $(3,5 \%)$ que contribui por meio de convênios com instituições de ensino.

De maneira geral pode-se pensar que existem indícios da realização de treinamento em algumas prefeituras, mas fica evidente a não oferta intencional de capacitações, capaz de retratar uma ação estratégica de desenvolvimento do funcionário. Observa-se a oferta e treinamento conforme necessidade de contingência ou oportunidades.

\section{Práticas de Remuneração}

Quando perguntado aos respondentes sobre a forma de remuneração utilizada pela administração municipal, e se há algum tipo de remuneração variável, os resultados sugerem que $62,1 \%$ dos municípios utilizam a remuneração funcional, ou seja, atrelada ao cargo que o funcionário ocupa. Para outros $(34,5 \%)$ há remuneração variável para alguns cargos, não chegando a especificar quais, e apenas um município $(3,4 \%)$ afirmou haver remuneração variável para todos os funcionários.

Em relação à existência de um Plano de Cargos, Carreira e Salários (PCCS), 34,5\% dos respondentes afirmaram que o município não possui essa ferramenta. Outros municípios $(20,7 \%)$ disseram que o PCCS está em fase de construção. Assim, para mais da metade dos municípios $(55,2 \%)$ não existe, ainda, uma política de cargos, carreira e salários formalizada. Tal política existe em $44,8 \%$ dos municípios. Foi possível identificar uma correlação positiva (Sperman) entre a existência de PCCS e o tamanho do município (0,424 - ao nível de significância 0,05$)$, sugerindo que quanto maior a população de um município, maior a probabilidade de possuir o PCCS.

Ainda em relação ao componente de remuneração, foi identificado que o tempo de prestação de serviço no município é um dos grandes componentes da progressão salarial, sendo afirmada a sua inexistência em apenas um município (3,4\%). A progressão por quinquênio é a mais habitual (65,5\%), sendo seguida pelo anuênio $(20,7 \%)$ e pelo triênio $(10,3 \%)$.

Já em relação à diferença salarial pela qualificação profissional, 44,8\% dos municípios responderam que tal prática existe para todos os funcionários, enquanto que em $31 \%$ dos municípios isso se aplica apenas a alguns funcionários. Embora a pesquisa não tenha explorado essa situação, há probabilidade de haver tal diferenciação aplicada aos profissionais da educação, em função da Lei 13.005 de 2014, que aprova o Plano Nacional da Educação e estimula que os municípios adaptem ou criem o Plano de Cargos, Carreiras e Salários para o Magistério. Vale destacar ainda, que praticamente um quarto dos municípios $(24,1 \%)$ não oferece diferenciação salarial por meio da qualificação profissional. Há correlação significativa $(0,05)$ entre o tamanho populacional do município e a existência de programa de diferencial salarial por qualificação profissional (correlação de Sperman).

Uma consideração torna-se necessária: utilizando o método de análise descritiva crosstabs foi 
possível identificar que todos os respondentes que afirmaram que o município não possui PCCS disseram que há progressão salarial por tempo de serviço prestado e $60 \%$ há progressão por qualificação. Dos respondentes que assinalaram que o PCCS está em fase de construção, 83,3\% afirmaram haver progressão por tempo de serviço e $66,6 \%$ por qualificação. Isso sugere a existência de algum ordenamento formal de ascensão de carreira ou salarial, pois é a única forma de ocorrer no ente público. Há que se considerar também a falta de compreensão da provocação por parte dos respondentes.

Quando indagado sobre o componente dos benefícios embutido na remuneração, analisou a oferta de planos de saúde complementares e alimentação (cesta básica e alguma outra forma de auxílio alimentação). Em relação à cesta básica, identificou-se a oferta a todos os colaboradores por $6,9 \%$ e cestas básicas a alguns trabalhadores a 3,4\% dos municípios. 89,7\% dos municípios não oferecem esse benefício. Quanto a alguma outra forma de auxílio alimentação, 62,1\% dos municípios não oferece o benefício, 3,4\% oferece a alguns funcionários e $34,5 \%$ oferece a todos os funcionários.

Quanto à possibilidade de um plano de saúde complementar, $27,6 \%$ dos órgãos municipais participantes oferecem o benefício. Embora envolva questões trabalhistas, a oferta de vale transportes também será analisada nesse tópico por ser também um benefício ao trabalhador, ainda que compulsório. Quanto ao vale transporte, $79,4 \%$ dos municípios não o oferece, enquanto que $10,3 \%$ oferece a alguns funcionários e outros $10,3 \%$ oferece a todos os funcionários.

É possível supor que em prefeituras de municípios com maior população, o que sugere um número maior de funcionários, os processos de gestão de pessoas são mais efetivos?. Para buscar resposta a essa provocação, realizou-se a análise de correlação de dados pelo método de Spearman, considerando a natureza das variáveis envolvidas e utilizando teste de significância com duas extremidades. Nessa análise, identificou-se que houve correlação com o número de habitantes do município, considerando valor $p$ de 0,01, as variáveis: oferta de auxílio alimentação $(0,487)$, oferta de vale transporte $(0,588)$, prefeitura possui setor de Serviços Especializados em Engenharia de Segurança e em Medicina do Trabalho - SESMT $(0,487)$, quantidade de trabalhadores no setor de $\mathrm{RH}(0,616)$ e quantidade de trabalhadores no setor de $\mathrm{RH}$ efetivos $(0,514)$. Considerando o valor $p$ de 0,05 , houve correlação do número de habitantes com: a oferta de treinamento de integração dos novos funcionários $(0,376)$, realização de treinamentos (técnicos) antes do início das atividades $(0,440)$, a existência de plano de cargos e carreiras $(0,424)$, diferenciação salarial por qualificação $(0,398)$ e oferta de treinamentos de atualização aos trabalhadores $(0,412)$. A análise de correlação é apresentada no Quadro 1.

Algumas das correlações observadas são explicadas pela demanda de serviços gerados pelo volume de funcionários públicos, observando que quanto maior a população do munícipio, maior a necessidade de servidores públicos. Assim, o setor de RH deve possuir mais trabalhadores, havendo a possibilidade de existir dissociado do Departamento Pessoal. Nessa mesma lógica, considerando demandas maiores relacionadas ao SESMT, justificando a existência de setor próprio. Há ainda uma variável facilmente compreensível que se trata da oferta de vale transporte, considerando as dimensões territoriais das cidades maiores. Vale destacar que pequenos municípios, em sua grande maioria, não dispõem nem mesmo do serviço de ônibus urbanos 
circulares. Pode-se ainda considerar que essa mesma distância entre diversos pontos da cidade se torna relevante quando da oferta de benefícios relacionados à alimentação, já que a alimentação nos domicílios torna-se mais difícil em função do deslocamento.

Quadro 1: Análise de correlações entre faixa da população municipal e variáveis associadas à Gestão de Pessoas nos municípios participantes.

\begin{tabular}{|c|c|c|c|c|c|c|c|c|c|}
\hline & $\begin{array}{c}\text { Faixa_popula } \\
\text { çắo }\end{array}$ & $\begin{array}{l}\text { Realiza_trein } \\
\text { amento_de_i } \\
\text { ntegração_do } \\
\text { s_novos }\end{array}$ & $\begin{array}{l}\text { Realiza_trein } \\
\text { amento_ante } \\
\text { s_do_inicio_d } \\
\text { as_atividades }\end{array}$ & $\begin{array}{c}\text { Periodicidade } \\
\text { _avaliaçåo_dd }^{\text {esempenho_- }} \\
\text { dos_funcioná } \\
\text { rios }\end{array}$ & $\begin{array}{c}\text { Prefeitura_av } \\
\text { alia_desemp } \\
\text { enho_de_seu } \\
\text { s_colaborado } \\
\text { res }\end{array}$ & $\begin{array}{c}\text { Funcionários } \\
\text { possuem_re } \\
\text { muneraçąa_v } \\
\text { ariável }\end{array}$ & $\begin{array}{c}\text { Quanto_ao_P } \\
\text { lano_de_carr } \\
\text { eiras_e_ecorre } \\
\text { to_afirmar }\end{array}$ & $\begin{array}{l}\text { Existe_diferen } \\
\text { ciação_salari } \\
\text { al_por_tempo } \\
\text { _de_serviço }\end{array}$ & $\begin{array}{c}\text { Existe_diferen } \\
\text { ciaçāo_salari } \\
\text { al_por_qualin } \\
\text { caçã̃o }\end{array}$ \\
\hline $\begin{array}{l}\text { Correlaçōes de } \\
\text { coeficiente }\end{array}$ & 1,000 & $376^{\circ}$ & $.440^{\circ}$ & .167 & .335 & ,113 & $.424^{\circ}$ &,- 289 & $398^{\circ}$ \\
\hline Sig. (2 extremidades) & & .045 & .017 &, 387 & .076 & .561 & .022 & .128 & .033 \\
\hline \multirow[t]{2}{*}{ N } & 29 & 29 & 29 & 29 & 29 & 29 & 29 & 29 & 29 \\
\hline & $\begin{array}{c}\text { Faîxa_popula } \\
\text { çăo }\end{array}$ & $\begin{array}{c}\text { Quanto_ao_P } \\
\text { lano_de_Carr } \\
\text { eiras_e_corre } \\
\text { to_afirmar }\end{array}$ & $\begin{array}{c}\text { Existe_diferen } \\
\text { ciação_salari } \\
\text { al_por_qualifi } \\
\text { caçẫo }\end{array}$ & $\begin{array}{l}\text { Existe_plano_- } \\
\text { de_saúde_co } \\
\text { mplementar }\end{array}$ & $\begin{array}{c}\text { Prefeitura_ofe } \\
\text { rece_cesta_b } \\
\text { ásica }\end{array}$ & $\begin{array}{c}\text { Prefeitura_ofe } \\
\text { rece_alguma } \\
\text { forma_de_a } \\
\text { uxilio_aliment } \\
\text { ação }\end{array}$ & $\begin{array}{c}\begin{array}{c}\text { Prefeitura_ofe } \\
\text { rece_vale_tra } \\
\text { nsporte }\end{array} \\
\end{array}$ & $\begin{array}{l}\text { Prefeitura_ofe } \\
\text { rece_ajuda_d } \\
\text { e_custo_para } \\
\text { _qualificaçáa }\end{array}$ & $\begin{array}{l}\text { Existe_mecan } \\
\text { ismo_de_inov } \\
\text { açăo_e_incen } \\
\text { tivo_a_sugest } \\
\text { ones_e_melho } \\
\text { rias }\end{array}$ \\
\hline $\begin{array}{l}\text { Correlaç̧óes de } \\
\text { coeficiente }\end{array}$ & 1,000 & $.424^{\circ}$ & $398^{\circ}$ & .120 & -.294 & $.487^{\prime \prime}$ & $.588^{*}$ &,- 150 & .219 \\
\hline Sig. (2 extremidades) & . & .022 & .033 & .536 & .121 & .007 & .001 & .438 & .253 \\
\hline \multirow[t]{2}{*}{$\mathrm{N}$} & 29 & 29 & 29 & 29 & 29 & 29 & 29 & 29 & 29 \\
\hline & $\begin{array}{c}\text { Faixa_popula } \\
\text { çấo }\end{array}$ & $\begin{array}{l}\text { Prefeitura_te } \\
\text { m_alguma_e } \\
\text { stratégia_de } \\
\text { reconhecime } \\
\text { nto }\end{array}$ & $\begin{array}{l}\text { Em_relação_- } \\
\text { a__pesquisa_- } \\
\text { de_clima_org } \\
\text { anizacional } \\
\end{array}$ & $\begin{array}{c}\text { Prefeitura_pro } \\
\text { vove_atividad } \\
\text { e_de_confrat } \\
\text { ernizaçăo }\end{array}$ & $\begin{array}{c}\text { Prefeitura_faz } \\
\text { celebração_- } \\
\text { dos_aniversa } \\
\text { riantes }\end{array}$ & $\begin{array}{l}\text { Prefeitura_po } \\
\text { ssui_setor_d } \\
\text { e_SESMT }\end{array}$ & $\begin{array}{c}\text { Sobre_EPI_a } \\
\text { prefeitura }\end{array}$ & $\begin{array}{c}\text { Prefeitura_ofe } \\
\text { rece_treinam } \\
\text { ento }\end{array}$ & $\begin{array}{c}\text { Prefeitura_de } \\
\text { stina_orçame } \\
\text { nto_Dara_trei } \\
\text { namento }\end{array}$ \\
\hline $\begin{array}{l}\text { Correlaçóes de } \\
\text { coeficiente }\end{array}$ & 1,000 & .336 & ,344 & .166 & .295 & $.487^{* \prime}$ & .061 & $.412^{\circ}$ & , 194 \\
\hline Sig. (2 extremidades) & . & .075 & .068 & 391 & 121 & .007 & .752 & .027 & .313 \\
\hline \multirow[t]{2}{*}{$\mathrm{N}$} & 29 & 29 & 29 & 29 & 29 & 29 & 29 & 29 & 29 \\
\hline & $\begin{array}{c}\text { Faixa_popula } \\
\text { çẵo } \\
\end{array}$ & $\begin{array}{c}\text { Prefeitura_po } \\
\text { ssui_Plano_d } \\
\text { e_treinament } \\
0\end{array}$ & $\begin{array}{c}\text { Prefeitura_rea } \\
\text { liza_entrevista } \\
\text { _de_desliga } \\
\text { mento }\end{array}$ & $\begin{array}{l}\text { Prefeitura_po } \\
\text { ssui_setor_e } \\
\text { specifico_de_ } \\
\text { RH } \\
\end{array}$ & $\begin{array}{c}\text { Quant. } \\
\text { Dessoas_qu } \\
\text { e_trabalham_ } \\
\text { no_RH }\end{array}$ & $\begin{array}{c}\text { Quant. } \\
\text { trabalhadore } \\
\text { s_do_RH_efe } \\
\text { tivos }\end{array}$ & $\begin{array}{c}\text { Formaçắa_do } \\
\text { _responsável } \\
\text { pelo_RH }\end{array}$ & $\begin{array}{c}\text { Área_da_form } \\
\text { açăo_do_res } \\
\text { ponsável_pel } \\
\text { O_RH }\end{array}$ & \\
\hline $\begin{array}{l}\text { Correlaçōes de } \\
\text { coeficiente }\end{array}$ & 1,000 & -218 & .311 & .353 & $.616^{\prime \prime}$ & $514^{*}$ & -.027 & -244 & \\
\hline Sig. (2 extremidades) & - & .257 & .101 & .060 & .000 & .005 & .895 & .231 & \\
\hline $\mathrm{N}$ & 29 & 29 & 29 & 29 & 29 & 28 & 27 & 26 & \\
\hline
\end{tabular}

** Correção significativa ao nível de 0,01; * Correlação significativa ao nível de 0,05

Quando se analisa efetivamente práticas de gestão de pessoas, a influência do tamanho populacional do município se aplica aos treinamentos (quer seja de integração, de início de atividades ou de atualização), à existência de planos de cargos e carreiras e também relacionados à forma de remuneração, considerando oportunidades de remuneração variável. Assim, municípios maiores tendem a ter algumas práticas de gestão de pessoas mais bem desenvolvidas.

\section{CONCLUSÕES}

O cenário da gestão de pessoas no serviço público municipal de prefeituras do Sul de Minas Gerais em muito se distancia do que é observado no mundo da iniciativa privada. Ainda que o setor público faça aplicações significativas de seus recursos em pagamento de pessoal, as práticas de gestão de pessoas ainda não refletem uma gestão eficiente.

Das três hipóteses iniciais do estudo, a saber: 1) As práticas de gestão de pessoas na administração pública municipal estão voltadas para o controle de pessoal (DP); 2) As prefeituras com mais de 100 mil habitantes, possuem práticas de gestão de pessoas mais bem elaboradas; 3) As prefeituras não possuem 
setor específico de Recursos Humanos/Gestão de Pessoas, apenas esta última não se confirmou, uma vez que, ainda que conjuntamente com o DP, apenas $24,1 \%$ dos municípios disseram não possuir o setor de RH.

Em relação às duas primeiras hipóteses, o que se observou é que a utilização de práticas voltadas para o controle de pessoal ainda se mostram como aquelas a que os profissionais mais se ocupam. Quando se consideram ações efetivas para preparação dos funcionários (práticas de treinamento), avaliação do desempenho e também remuneração, o que se constata são poucas atividades estratégicas. Apenas um terço dos municípios afirmaram realizar avaliação de desempenho sistemática de seus trabalhadores, 7\% provavelmente possuem uma programação de treinamento intencional e 3,4\% utilizam de forma geral práticas de remuneração que fogem do modelo funcional.

Validando a segunda hipótese do estudo, diferença é observada em relação a municípios com maior população, onde práticas mais consistentes são observadas, tanto em relação a treinamento, quanto a formas de remuneração. Não foi observada correlação significativa entre a realização de avaliação de desempenho dos municípios e seu tamanho populacional.

Este estudo parte das respostas emitidas pelos respondentes de cada município. Buscou-se identificar o cargo dos respondentes para minimizar o risco de respostas que não retratassem a realidade daquela prefeitura, porém, não se elimina o risco. Salienta-se como limitação desse estudo o fato da amostra ser aleatória por conveniência o que não permite generalizar os resultados para todo o território pesquisado. Indica-se para futuras pesquisas a abordagem mais ampla e estatisticamente fundamentada desde a amostragem.

\section{REFERÊNCIAS}

ANDRADE, E.. Gerenciamento de processos para melhoria da eficiência na administração pública: estrutura de referência para a UTFPR. Dissertação (Mestrado em Planejamento e Governança Pública) - Universidade Tecnológica Federal do Paraná, Curitiba, 2017.

ARAGÃO, C. V.. Burocracia, eficiência e modelos de gestão pública: um ensaio. Revista do Serviço Público, Brasília, v.48, n.3, p.104-132, 1997.

BERGUE, S. T.. Gestão de pessoas em organizações públicas. 3 ed. Caxias do Sul: EDUCS, 2010.

BERGUE, S. T.. Gestão Estratégica de Pessoas no Setor Público. São Paulo: Atlas, 2014.

BRASIL. Lei Complementar n.101 de 4 de maio de 2000. Estabelece normas de finanças públicas voltadas para a responsabilidade na gestão fiscal e dá outras providências. Brasília: DOU, 2000.

BRESSER-PEREIRA, L. C.. Estratégia e Estrutura para um Novo Estado. Revista de Economia Política, São Paulo, v.17, n.3, p.24-38, 1997.

BRESSER-PEREIRA, L. C.. Uma reforma gerencial da administração pública no Brasil. Revista do Serviço Público, Brasília, v.49, n.1, p.5-42, 1998.
CARMO, L. J. O.; ASSIS, L. B.; SANCHES JUNIOR, P. F.. Gestão Estratégica de Pessoas no Setor Público: Um Estudo de Caso sobre Limites e Possibilidades em uma Autarquia. In: ENCONTRO DA ASSOCIAÇÃO NACIONAL DE PÓS GRADUAÇÃO E PESQUISA EM ADMINISTRAÇÃO, 38. Anais. Rio de Janeiro: EnANPAD, 2014.

CNM. Confederação Nacional dos Municípios. A crise dos municípios Brasileiros: Estudo Técnico. Brasília: CNM, 2017.

LACOMBE, F.. Recursos Humanos: princípios e tendências. Saraiva: São Paulo, 2006.

LINN JUNIOR, L. E.. Gestão Pública. In: PETERS, B. G.; PIERRE, J.. Administração Pública: coletânea. Brasília: ENAP, 2010.

MARCONI, M. A.; LAKATOS, E. M.. Fundamentos de metodologia científica. 6 ed. São Paulo: Atlas, 2005

MATIAS-PEREIRA, J.. Administração pública comparada: uma avaliação das reformas administrativas do Brasil, EUA e União Europeia. Revista de Administração Pública, Rio de Janeiro, v.42, n.1, p.61-82, 2008

MOREIRA NETO, D. F.. Quatro paradigmas do direito administrativo pós-moderno: legitimidade: finalidade: eficiência: resultados. Belo Horizonte: Fórum, 2008.

MOTTA, P. R.. Gestão Estratégia. In: VERGARA, S. C.; CORRÊA 
V. L. A.. Propostas para uma gestão pública municipal efetiva. Rio de Janeiro: FGV, 2004.

RUDIO, F. V.. Introdução ao projeto de pesquisa científica. 17 ed. Petrópolis: Vozes, 1992.
ULRICH, D.. Os campeões de Recursos Humanos. Inovando para obter os melhores resultados. São Paulo: Futura, 1998.

ULRICH, D.; YOUNGER, J.; ULRICH, M.; BROCKBANK, W.. RH de Dentro para Fora: Seis Competências para o Futuro da Área de Recursos Humanos. São Paulo: Bookman, 2011.

A CBPC - Companhia Brasileira de Produção Científica (CNPJ: 11.221.422/0001-03) detém os direitos materiais desta publicação. Os direitos referem-se à publicação do trabalho em qualquer parte do mundo, incluindo os direitos às renovações, expansões e disseminações da contribuição, bem como outros direitos subsidiários. Todos os trabalhos publicados eletronicamente poderão posteriormente ser publicados em coletâneas impressas sob coordenação da Sustenere Publishing, da Companhia Brasileira de Produção Científica e seus parceiros autorizados. Os (as) autores (as) preservam os direitos autorais, mas não têm permissão para a publicação da contribuição em outro meio, impresso ou digital, em português ou em tradução. 